Biology | Dr Bertrand Lemasson

\section{How a minority can swiftly shape collective actions}

Understanding how groups of animals react to sudden threats has eluded researchers for many years and previous models failed to provide mechanism for how social quickly through the ranks. For the past ten years, $D$ Bertrand Lemasson, based at the U.S. Army Engineer Research and Development Center in Oregon, USA, has studied how and when an individual's actions within a group merit attention whd the consequences for

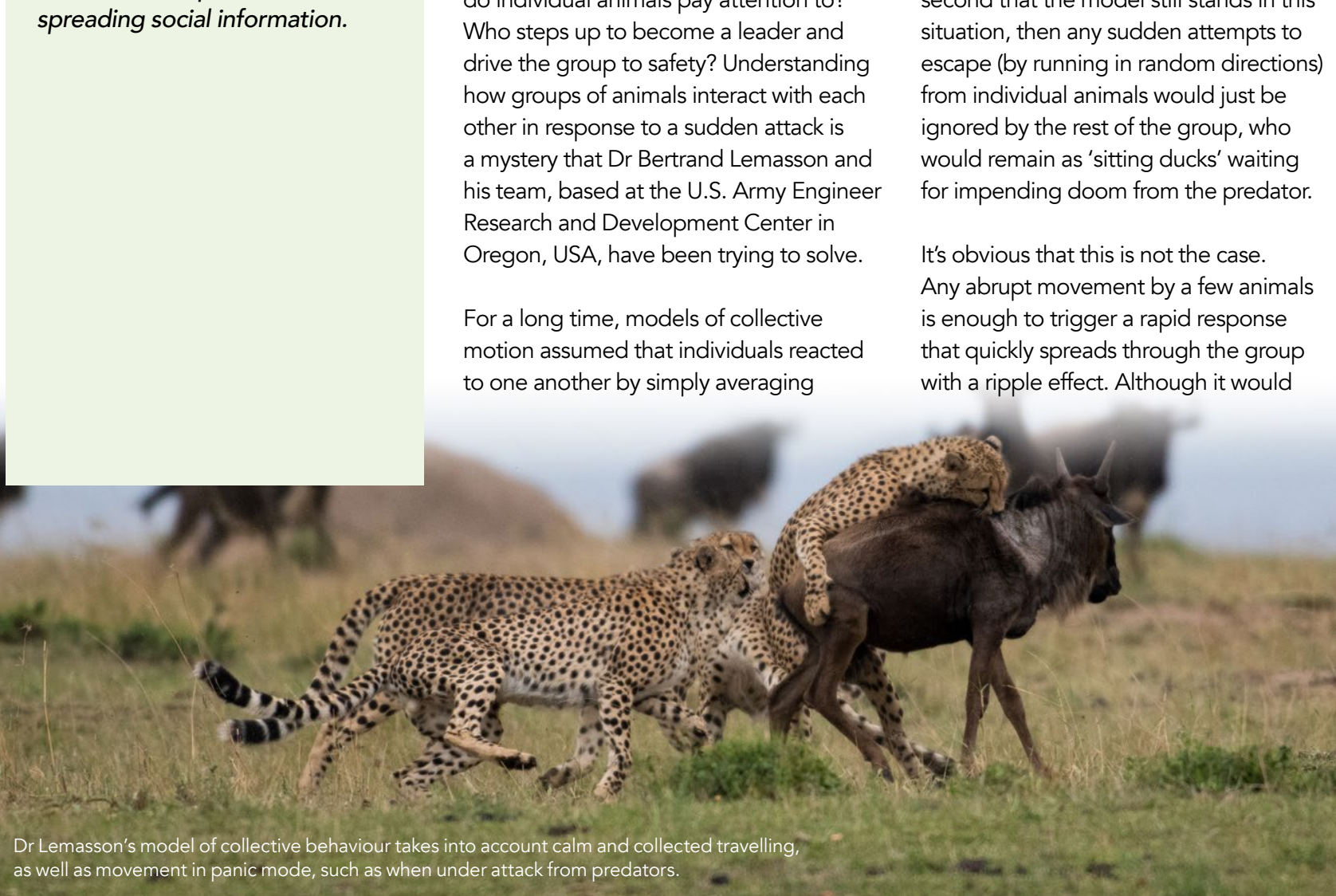

the actions of their neighbours. This approach keeps things simple, which scientists like, and it is good enough outperform individual ones during individual mistakes are cancelled smat as the rest of the group maintains course. Under these conditions a minority can bias a group's direction, but only if they are persistent for a prolonged period of time. This simplistic view, however, fails miserably when a predator attacks and time is of the essence. Imagining for a

this is not the case. when there's a predator lurkng

In the midst of the chaos and confusion to explain why group decisions often like migratory birds for shares a goal,

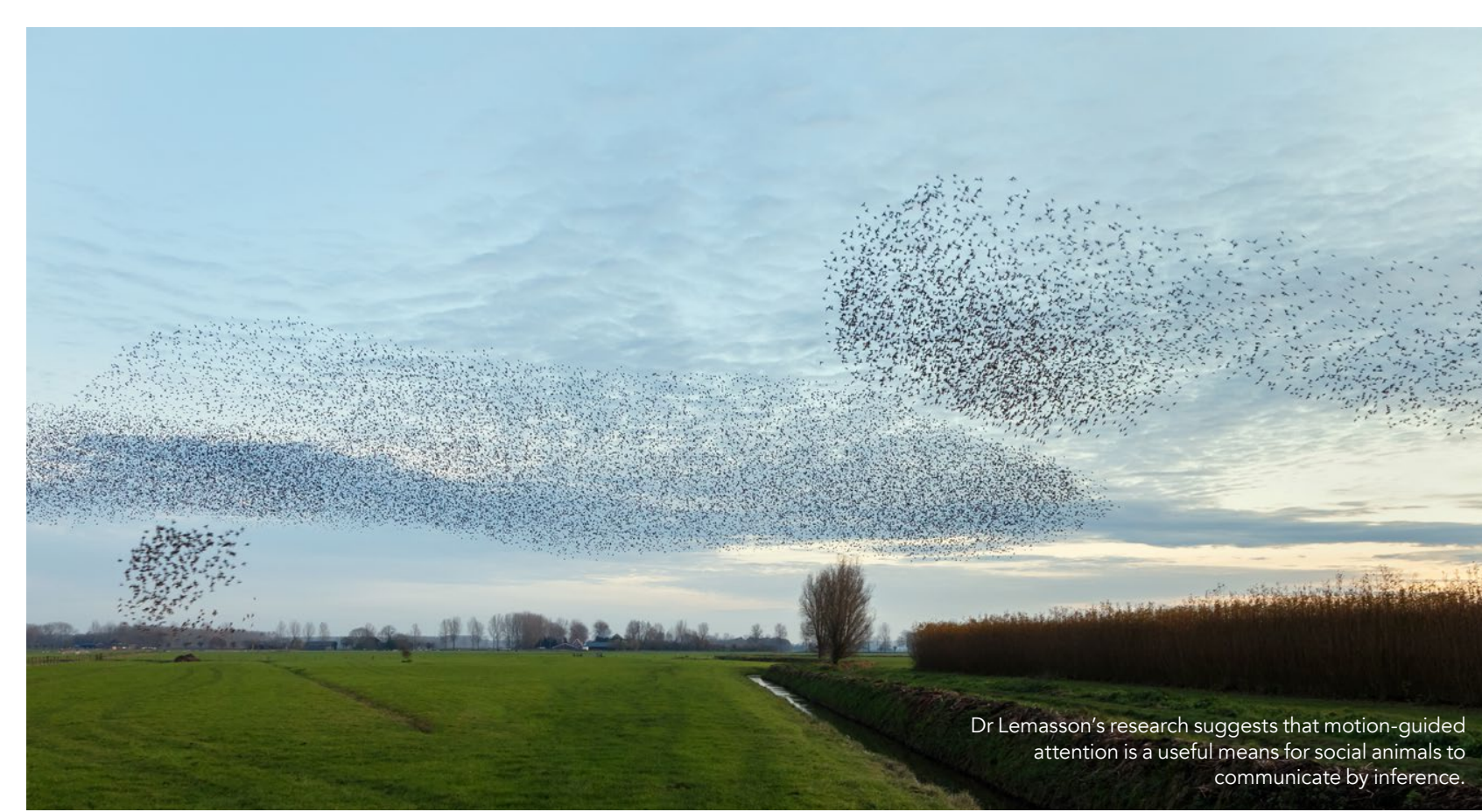

explain much more than the previous model, this new idea brings its own set of unresolved questions: how much attention do animals pay to their ones are worth following?

For Dr Lemasson, the answer may lie in how animals can spot movement around them. In 2013, the team proposed that animals traveling in group likely follow those that stand out from the crowd. From an animals point of view, all others moving at the same speed are unlikely to be providing any new
information. However, the neighbour that information. However, he neighbour that suddenly takes off in haste likely knows
something that its neighbour doesn't1

Crucially, Lemasson's model covers both calm and collected travelling as well as panic mode under attack by a predator. When all animals move at the same speed, neighbour actions are equally integrated and democratic decisions dominate. A motion-based mechanism also suggests a way to reduce the risk of false alarms - that is, having individuals waste valuable energy by responding to threats that aren't there. However, in the event of a kerfufle, animals will preferentially follow those that spotted the danger, triggering behavioural changes that cascade across the group. In this case, the majority is ignored to follow a minority.

\section{FOLLOW EXTREME BEHAVIOUR} OR BE AVERAGE?

For Dr Lemasson, the first step to test his model was to confirm the importance of visual cues. Using a computer model starting with individuals in random positions (mimicking animals foraging),
it was possible to "make" any individua go from zero to hero in just seconds, simply by having it accelerate and instantly attracting the attention of not also draw a predator's gaze? Using the midst of the chaos and confusion that can arise during an attack, who do individual animals pay attention to?

nearby neighbours. In a way, although a computer again, the team developed the first animal was only looking out for a a game' where players had to track itself and had no intentions of becoming and catch prey.

a leader, temporarily it became the main source of information for the Ironically, as much as a coordinated $\begin{array}{ll}\text { rest of the group. Dr Lemasson called } & \text { group approach seems like a strong bet } \\ \text { this intuitive communication system } & \text { against potential attacks, this consistent }\end{array}$

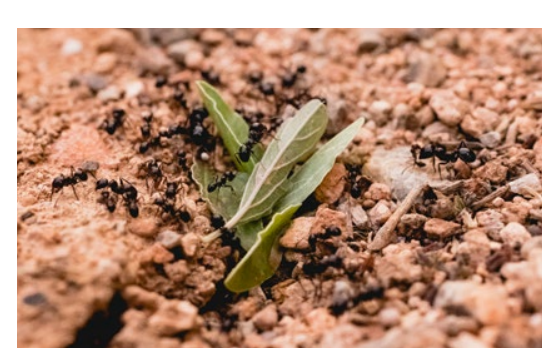
What are the signals
for their neighbours?

mongst members of a group motionPREDATOR VS. PREY

to test his hypothesis involved analysing not only how prey reacted to visual cues. nontion of ones' neighbours, could they 


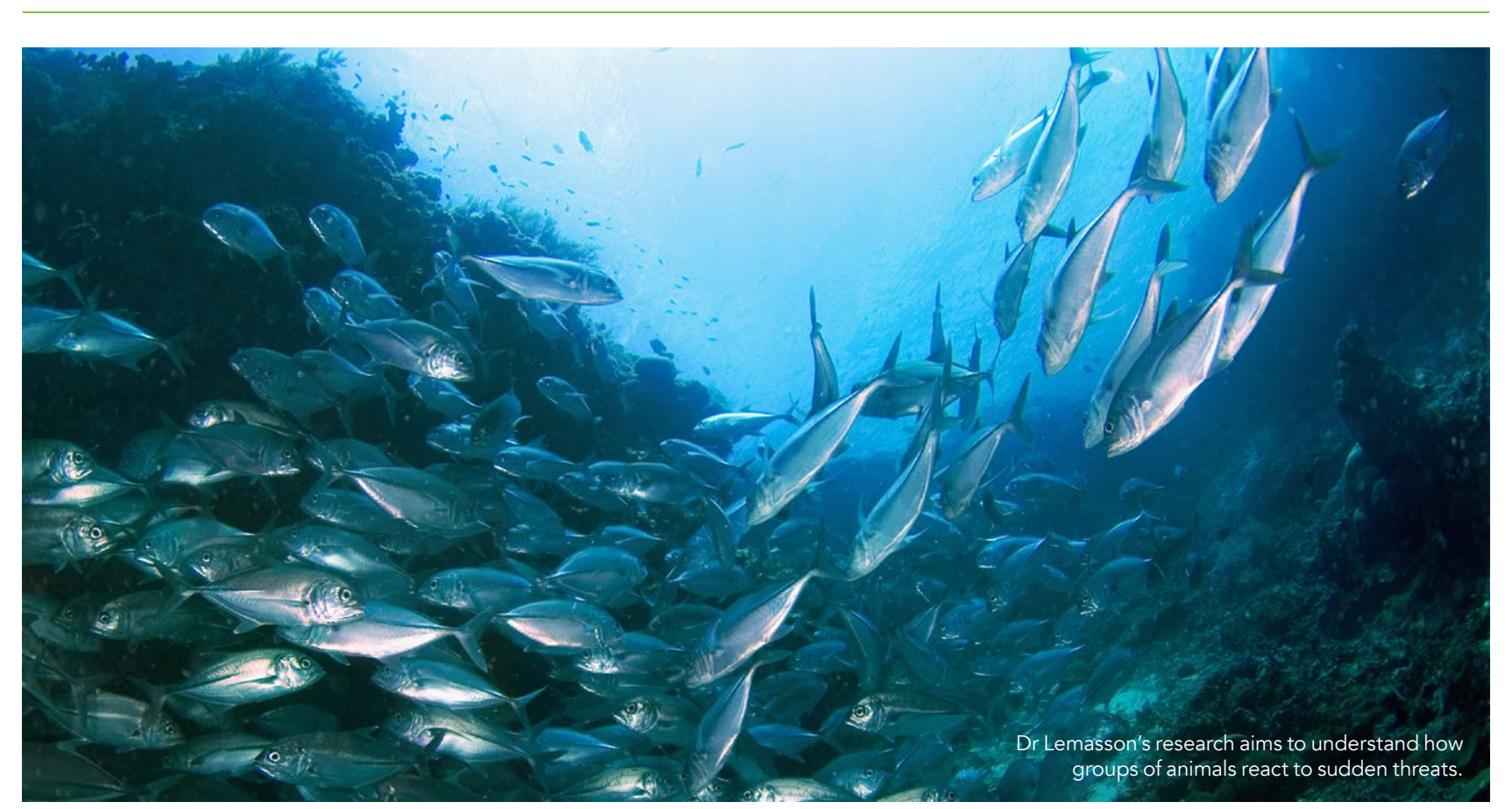

Crucially, Lemasson's model covers both calm and collected travelling as well as panic mode under attack by a predator.

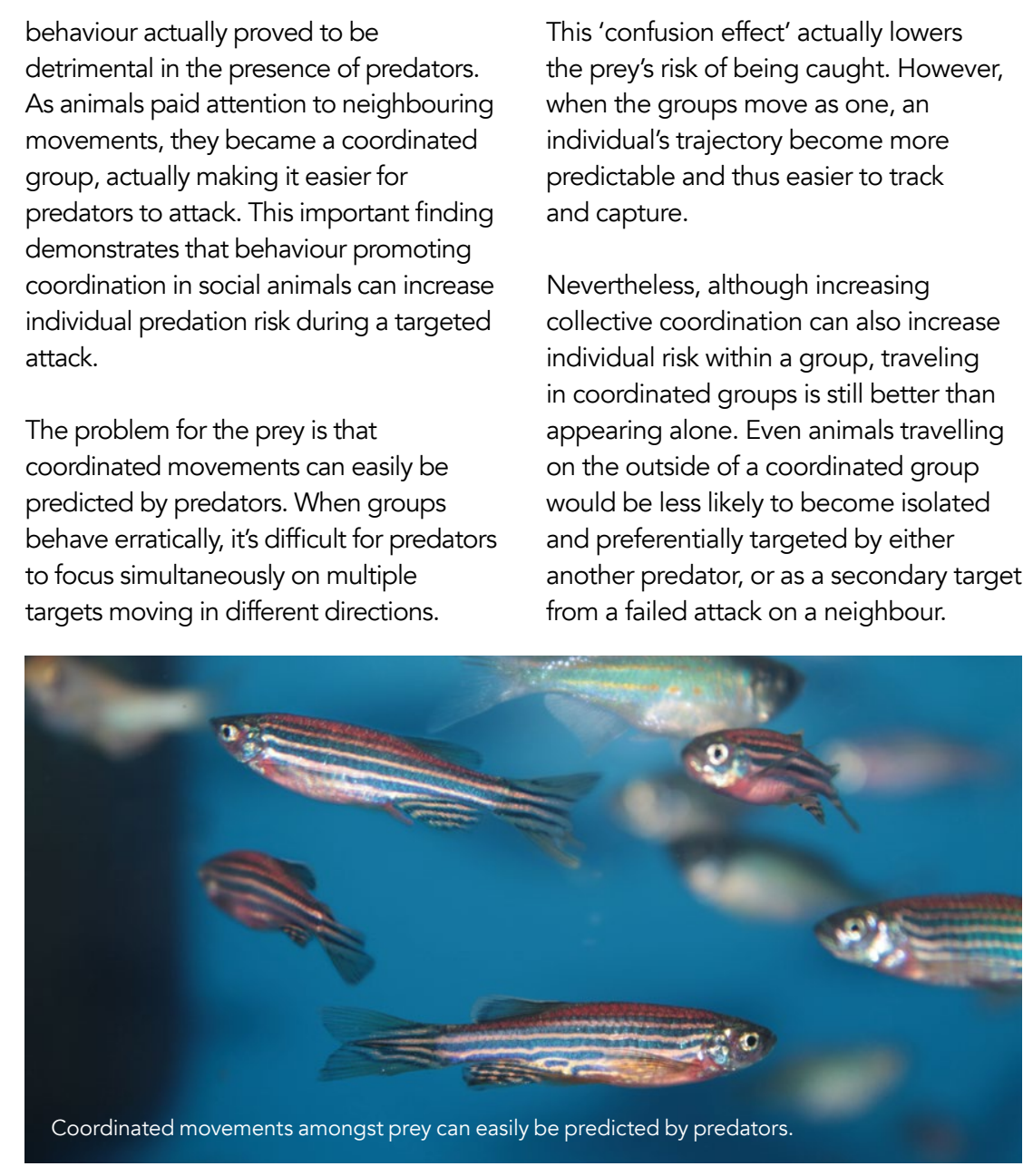

FINALLY, THE EVIDENCE NEEDED Moving on from computer simulations, Dr Lemasson and his team recently tested their hypothesis in real fish schools. The challenge was to determine how
animals react to changes in the speed of a neighbour. The team placed zebrafish (alone or in groups) in a Y-shaped maze and projected virtual shoal mates onto the bottom of the maze. Virtual fish were divided into 'distractors' that moved randomly when it was time to decide to go left or right, and 'leaders' or or the other.

When the 'leaders' moved at the same speed as the rest of the group, the rule and followed the majerty of their neighbours. However, when the leaders moved faster, zebrafish would almost always follow them, regardless of what the rest of the group (real and virtual) was doing. While researchers have known for a long time that vision plays an importan role in fish behaviour, Dr Lemasson's team demonstrated for the first time how perceived changes in speed can tune the strength of social interactions.

Despite the growing body of evidence supporting Dr Lemasson's model questions still remain as to how individuals living in groups, particularly those on the move, can decide which neighbours to follow
neighbours to ignore.

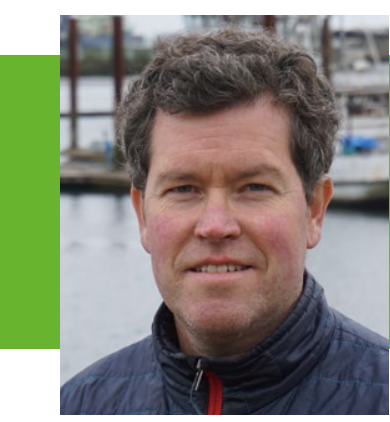

\section{Behind the Research}

\section{Dr Bertrand Lemasson}

E: brilraven@gmail.com T: +1 503 360-8223

\section{Research Objectives}

Dr Lemasson's research into collective animal behaviour extract pertinent information from the many social cues that

\section{Detail}

Bio

Bertrand Lemasson received his Ph.D. in ecology from Uta State University in 2007 where he studied the behavioura algorithms fish use to navigate their environment, either alone or in groups. He then did a postdoc in the School of Aquatic \& Fishery Sciences at the University of Washington before joining the Ecohydrology and Cognitive Ecology Team in ERDC's Environmental Laboratory.

\section{Funding}

This research was conducted under the Environmental Quality and Installations Basic Research Program of the U.S. Army Corps or Engineers by the U.S. Army Engineer Research and Development Center (ERDC). The authors express gratitude to Dr Elizabeth Ferguson, Technical Director of the U.S. Army ERDC Environmental Quality Dre

\section{Collaborators}

Andrew Goodwin, Dr Colby Therer, Dr Chista WrAndey, and Dr David Smith at various stages.

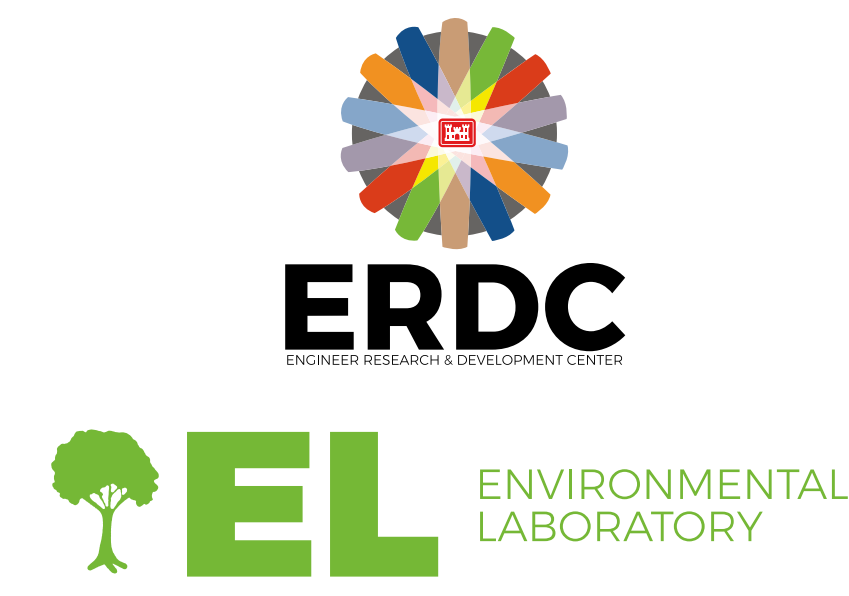

References

Lemasson, BH, Anderson, JJ and Goodwin, RA (2008) Collective motion in animal groups from a neurobiological perspective: The adaptive benefits of dynamic sensory loads and selective attention. Journal of Theoretical Biology 261, 501-510. doi: 10.1016/j.jtbi.2009.08.013.

Lemasson, BH, Anderson, JJ and Goodwin, RA. (2013) Motion-guided attention promotes adaptive communications
during social navigation. Proc. R. Soc. B, 280, 20122003. doi: 10.1098/rspb.2012.2003.

Lemasson, BH, Tanner, CJ, Dimperio E (2016) A Sensoryand a Predator's Visual Confusion. PLOS Computational Biology, 112(2), e1004708. https://doi.org/10.1371/journal. pcbi. 1004708 .

Lemasson, BH, Tanner, C, Woodley, C, Threadgill, T, Qarqish, $\mathrm{S}$, Smith, D (2018) Motion cues tune social influence in s41598-018-27807-1.

\section{Personal Response}

\section{What sets the threshold speed to follow a neighbour} moving faster? Or in other words, when does
individual animal decide it's time to follow?

II Actually, we still don't know if the responses we observed reflect a threshold, a weighted decision, or some other mechanism that enables individuals to quickly sist hrough alternative stimull. That will entail measuring moving animals. What we have established is that these fish preferentially respond to visual cues that are moving much faster than others found in their field of view. This is an important start and makes biological sense. You see, most social information in animal groups is passively whether following a neighbour has any value. Sudden bursts of motion are really quite expensive, energetically speaking and so animals tend to use them sparingly. As such, speed provides individuals with a natural means of weighing
the value of a neighbour's actions. 